\title{
HUR SCHOTTIS BLEV BONNJAZZ, eller hur svensk foxtrot besegrade jazzen, eller har afro-amerikansk musik funnits i Sverige?
}

Svenskfolkmusik • schottis • onestep • jazz • bonnjazz • afro-amerikansk • ungdomsmusik • ackulturation • dichotomier

Under senare hälften av 1800-talet dansades i Norden flera olika danser: schottis, pas de quatre, jänka $\mathrm{m}$ fl. Sätten att dansa dem varierade något, medan musiken till de olika danserna var mycket snarlik (se exempelvis i Lekstugan, utgiven av Sällskapet Svenska Folkdansens Vänner, 1903). Några generationer senare, på 1920-talet dansade man runt om i Sverige fortfarande till en musik som lät förvillande lik dessa gamla melodier. Men nu kallades denna musikstil för bonnjazz. Hur detta gick till, hur snarlika musikstrukturer kan vara bärare av olika tidsanda, men trots detta ha liknande funktioner, samt hur den utifrån kommande dans- och ungdomsmusiken har uppfattats i Sverige fram till 1980-talet är något av det viktigaste som denna artikel vill berätta om.

\section{Var schottis svensk folkmusik?}

Under början av 1800-talet formas inom den framväxande borgarklassen uppfattningen att svensk folkmusik var bärare av äkta, uråldriga och nationalistiskt svenska drag. Man började därför att fara runt bland allmogen 
och skriva ned deras musiktradition. Många av dessa nedteckningar kunde den bildade och musikintresserade borgerligheten ganska snart ta del i form av olika utgåvor. Som regel lades ett enkelt pianoackomanjemang till visorna, ibland enligt tidens rådande musiksmak, ibland med mer känsla för sångernas egenvärde (Ling 1979). Efterhand prövade både amatörer som kompositörer att skriva sånger och senare även instrumentalstycken i en svensk, eller nordisk folkmusikstil (Helmer 1972, Öhrström 1987).

Melodier som "Neckens polska" och andra, dvs polskor, men även valser och marscher, och då helst i moll, bildade efterhand en tradition som betraktades som en närmast evig svensk folkmusik. Man var däremot inte lika intresserad av melodier som gick i dur och hade ett nyare snitt, även om de sjöngs bland allmogen. Denna musik passade inte in i den verklighetsbild man skapat.

Precis som valsen först dansades ut i herrskapssalongerna, prövades andra nya modedanser som polka, pas de quatre, schottis, rheinländer $\mathrm{m} \mathrm{fl}$ först av adliga och borgerliga fötter, innan de togs upp av andra befolkningsgrupper. De senare danserna beskrivs som varianter av polkan. Skillnaden mellan dem och deras resp ursprung och historia synes inte vara helt glasklar. Som Czerny \& Hofman (1968) nämner fanns i Tyskland en dans i rask 2/4-takt, hopser, som var omtyckt och som ibland också benämndes schottis (schottisch). Denna var därför inte, vilket namnet verkar antyda en skottsk dans. Enligt Groove's lexikon, kom dansen till England år 1848 och kallades då för "German Polka". I Sverige, skriver Sohlmans lexikon, blev schottis känd i mitten av seklet, och dansades i ett något långsammare tempo än polka. I södra Sverige och i Norge kallades samma dans för rheinländer, eller renländare, rillen m fl namn (se Lekstugan 1903:22). Denna dans, skriver Czerny \& Hofman, var egentligen en särskild tysk variant av polkan ("Rheinländerpolka" eller "Bayrische Polka", som de anser inte fanns i något annat land! /1968:23/). Pas de quatre, å andra sidan, var ursprungligen en engelsk dans, som under 1800-talets andra hälft blev en fransk modedans (Sohlmans 1979). Det tilläggs att dansen i Sverige blev känd tack vare att den förekommer i Hallströms opera "Den bergtagna" (1874). Men inte heller den sista informationen, finns det anledning att helt tro på, eftersom pas de quatre förekommer på programmen från Berns berömda musiksalon under 1860-talet! Att pas de quatre, dessutom här kallas för "engelsk sjömansdans" gör inte saken sämre. Säkerligen var Berns inte det enda ställe i Sverige som pas de quatre framfördes på. Observera att det på programmet också förekom sång av "Amerikanska Negersångare": 


\section{BERNS SALON}

Fredagen den 22 februari 1867.

\section{Program}

Första afdelningen:

1. Ouverture till Jean de Paris af Boildieu.

2. Gally Fire, sjunges af de Amerikanska Negersångarne

3. Comic Song, Betzy Gay, sjunges af M:r Kelly

...

7. Engelsk Sjömansdans, Pas de quatre, dansas af Elev. Axel Kihlberg, Erik Wibom, Anna Hagberg och Hanna Zinz.

Om än historieskrivningen är förvirrande, står det klart, att både schottis, rheinländer som pas de quatre - i folkmun ofta kallad paddekatt - i slutet av 1800-talet, men även i början av 1900-talet var mycket populära dansmelodier bland bonde- och arbetarbefolkningen, men sannolikt mindre bland borgerliga kretsar. Att döma av skildringarna av danserna, och de tryckta dansprogrammen i borgerliga (och adliga) hem under 1800-talet förekommer nämligen schottis/pas de quatre mera sällan (se Rosenquist 1948:2150). Som Martin Tegen (1986) nämner dyker schottis först upp under 1880-talet i de dansalbum, som köptes av den danslystna borgarklassen. Kring sekelskiftet däremot trycktes det mycket nothäften med schottis etc, vilket den stora utgivningen från tidens stora musikförlag som Abr Lundquist förlag, Carl Johnns förlag, Elkan \& Schildknecht m fl. vittnar om. Melodierna kallas än för schottis, pas de quatre, eller rheinländer eller för kombinationer av dessa begrepp. Dessa stycken, sannolikt oftast utgivna enbart för piano, består som regel av en kort introduktion, en till tre repriser på 16 takter, ibland med en trio som oftast går i annan tonart, varefter de första repriserna tas da capo. De går nästan alltid i dur och som regel i 2/4-takt.

1. Min tös. Schotish-pas-de-quatre. Otto Hultner

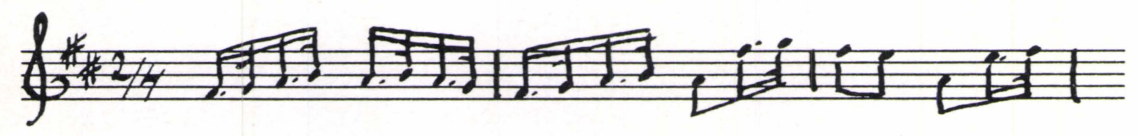




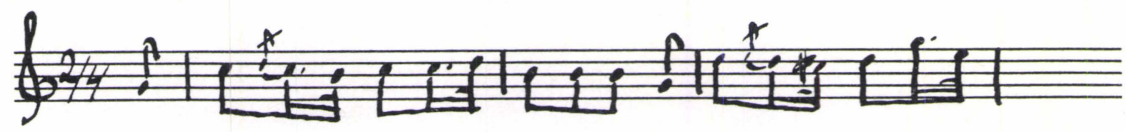

3. Schottisch från Nyed. Pas de quatre. Arr. A Söderberg

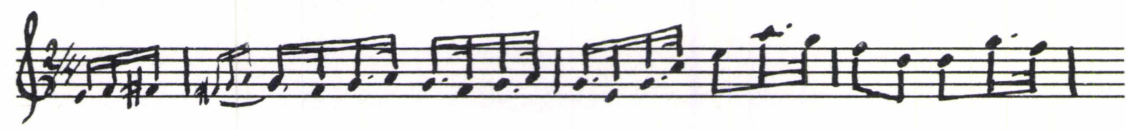

Några exempel på början av de första repriserna i olika "schottis".

På omslagsbilderna till dessa nothäften syns ofta en svensk pojke och flicka i nationalkläder inramade av vacker natur, drängar och pigor som dansar, några glada beväringar, eller andra motiv som ger associationer till svensk frisk ungdom/svensk lantlig idyll. Dylika omslagsbilder mötte man också för svenska valsmelodier (gammaldans), hambo, polketter osv.

Det musiken betydde, byggdes upp kring dess struktur, dess plats och funktion. Man kunde således av nothäftena se att musiken var svensk, och man hörde av tonerna att det var svensk musik, om än med lantlig anstrykning. För den tidens publik: för borgarskapens flickor som satt och övade på melodierna, för publiken som hörde Wermlands regementes musikkår spela "En nutida Frykdalsdans" på en uteservering i Stockholm, eller för statarungdom på dans på en loge, var denna musik därför så svensk som någon musik kunde vara. Den sistnämnda publiken, liksom bondebefolkningen överhuvudtaget, fick väl sällan eller aldrig syn på notomslagen, men de visste ju att musikerna som spelade, var från den egna socknen eller trakten, att melodierna hade svenska titlar, och de kände igen musiken som sin egen eftersom de vuxit upp med den. Tanken att schottis, paddekatt etc inte var svensk musik var därför otänkbar för dem. Vad skulle den annars vara? Men tänkte man på denna musik som sin egen folkmusik? Nej, sannolikt inte; för borgerligheten var ju folkmusik detsamma som svenska folket gamla molltyngda melodier, medan "folket" a sin sida, inte betraktade sin egen musik från ett analyserande utanförsperspektiv.

När därför Nils Andersson i slutet av 1800-talet drar ut på uppteckningsfärder efter svensk folkmusik, vill han i första hand höra polskor, vals och och marsch och då helst i sångversioner, eller på nyckelharpa, fiol och klarinett. Nyare låtar och dansmelodier, i sämsta fall spelade på dragspel, 
eller munspel ville han helst slippa höra (Ling 1979, 1980). Kring sekelskiftet kommer skilda aktiviteter igång; bildandet av dansförbund, en folkmusikkommission bildas, spelmansstämmor/tävlingar startar etc, som på olika sätt bidrar till, bygger vidare på och konsoliderar den under 1800talet uppkomna uppfattningen om vad svensk folkmusik är eller skall vara.

Så kommer det sig, att schottis, pas de quatre, rheinländer inte har några försvarare, att denna musik inte har status av svensk folkmusik, men att musiken under det första decenniet är mycket populär, spelas och dansas till både inom bondebefolkningen, arbetarklassen, lägre och övre medelklass. En och annan får också text, exempelvis Otto Hultners melodi "Min tös", (Abr Lundquists förlag) som Felix Körling kläder i ord. Denna schottis hade stor succé under 1903, men spelades under hela decenniet, liksom de "Frykdalsdanser", dvs rheinländer som musikdirektören Ernst Willners gav ut under eget namn och hade sådan lycka med. När sångaren Ernst Rolf i början av 1910-talet startade ett eget musikförlag, som snart skulle bli den tidens ledande förlag för populära sång- och dansmelodier, eller schlager, som man alltmer kallade dessa melodier för, så gav han också ut en och annan schottis. Men han liksom de flesta andra förlag inriktade snart sin verksamhet mot annan dansmusik av utländsk ursprung: bostonvals, twostep, onestep, tango $\mathrm{m}$ fl. Intresset för denna nya dansmusik går hand $\mathrm{i}$ hand med långsamma förändringar i samhället. Martin Tegen karaktäriserar allmänt musikkulturen under tiden 1890-1910 i Stockholm med slagorden demokratisering, kommersialisering och popularisering (1955). För dansmusikens del innebar det bl a att en offentlig dansbana öppnades vid Stockholms-utställingen sommaren 1909, en under samtiden mycket uppmärksammad företeelse. Den stora modedansen i de stora städerna var då sedan några år tillbaka den relativt långsamma bostondansen. Vid samma tid kommer det också in dansmelodier i 2/4-takt som kallas för twostep. Ibland är de tänkta i två delar, och kallas då marsch och twostep, intermezzo och twostep, men det förekommer också många gånger tilläggsbeteckningar som fish walk, bear dance $\mathrm{m} \mathrm{m}$. Några år därefter anländer en snabbare variant av twostep kallad onestep.

Dessa melodier har i början aldrig text. Det blir vanligare först på 10talet. De börjar oftast med en kort introduktion, följt av en till tre repriser, som regel på 16 takter var. Ibland kallas den sista reprisen för "trio". Här följer några korta exempel: 


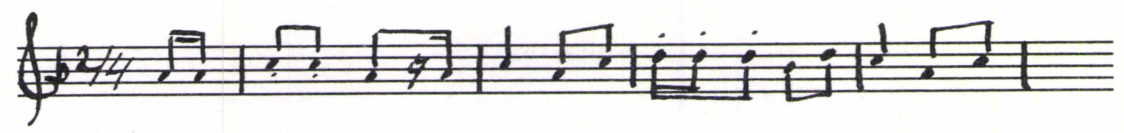

5. "Ticke-Ticke". Two step. Theodor Pint.

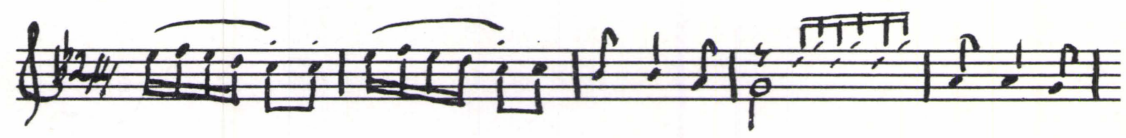

6. The Yankee Doodle boy. March and Two-Step. G C Cohan

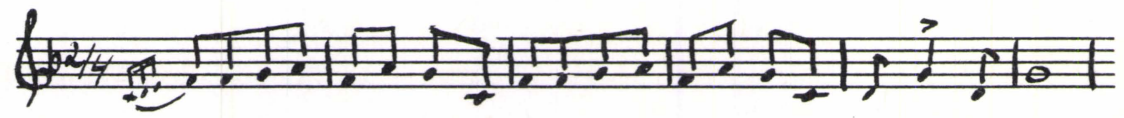

Början av några step från seklets början.

Som synes är dessa musikexempel ur strukturell synpunkt ganska snarlika schottis, pas de quatre, rheinländer, men också polka. Men de uppfattades som nyheter och kunde spridas relativt snabbt tack vare nya media som stumfilm (- med "levande" musik!) och grammofon. 1910-talet blev onestepens, men beroende på det första världskriget, även marschens årtionde. Dansen onestep gick således $i$ ett snabbare tempo än twostep, men fordrade heller inte några lång kurs för att lära sig:

1915 demonstrerade Lisa Holm-Bryde och Oscar Tropp onestep på film. Den amerikanska dansen hade nämligen börjat slå igenom på allvar, vilket väckt en storm av protester från konservativt håll. Manfred Björkquist kallade onesteppen "parningslek", ett upprop "Bort med onesteppen!" utfärdades. (Rosenquist 1948:2152)

Obekymrade av vad "moralens väktare" ansåg om onesteppens osedlighet fortsatte människorna i städerna att dansa den, liksom man på landsortens dansbanor fortsatte att dansa valser, schottis, hambo etc. Efterhand nådde de nya dansmusikstilarna också ut på landsbygden; någon hade varit i staden och sett hur det gick till, någon hade hört en skiva spelas med onestep, någon hade hört en onestep spelas av ett restaurangkapell osv. Eftersom amerikanska onestep som regel innehåller synkoper, en rytmisk egenskap som är lätt att lägga märke till, ligger det därför nära tillhands att se 
onestep som det första exemplet på afro-amerikansk musik.

Någon allmän accepterad definition av vad som skall räknas som afroamerikansk musik finns inte (se Lilliestam 1984). Som jag ser det, ligger en förklaring till detta $\mathrm{i}$ att begreppet ofta ses som statiskt, medan det $\mathrm{i}$ själva verket är nödvändigt att alltid definiera det utifrån ursprungsgruppens användning av ordet under den tidsperiod som diskuteras. I början av seklet förstår jag med afro-amerikansk musik den folkmusik, work song, blues, gospel etc, som vuxit fram bland den färgade befolkningen i södra USA. Ju längre fram under 1900-talet vi går, desto fler drag från den vita populärmusikkulturen påverkar den afro-amerikanska musiken, och går upp i denna. För den färgade storstadbefolkningen på 1960-talet uppfattas därför deras s k "soul music" som en afro-amerikansk musik, även om dess struktur och funktion har förändrats.

Den afro-amerikanska folkmusiken gav i slutet av 1800-talet bl a näring åt en ny populärmusiktyp, ragtime, sammansatt av afro-amerikanska och europeiska element. Ragtime var i sin tur utgångspunkten för flera nya dansmusikstilar, bland dem twostep och onestep, som emellertid huvudsakligen skrevs av vita musiker för att lanseras för en så stor publik som möjligt. Denna populära dansmusik hade därför vissa strukturella afroamerikanska drag. Onestep karaktäriseras således av den amerikanska musikforskaren Charles Hamm som "tanklösa, livliga, lätt synkoperade, luftiga och nästan alltid humoristiska" ( 1979:321 /min översättning/). Men frågan är om onestep eller överhuvudtaget ragtime-liknande musik på 1910-talet uppfattades ha några afro-amerikanska drag av den svenska publiken.

Det som något talar för att det kan ha funnits en associationskedja mellan denna musik, färgade i USA och Väst-afrikanska eller Afrikanska stamfolk (söder om Sahara) är de musikstycken av typen "intermezzo", som ibland handlade om exotiska folk och händelser. Dessa stycken spelades både $\mathrm{i}$ hemmen, på caféer och restuaranter. Av följande utdrag ur "Eine vergnügte Negerhochzeit" (Ett glatt negerbröllop) komponerad 1902 av R Vollstedt (opus 215) framgår den ragtime-liknade strukturen klart:

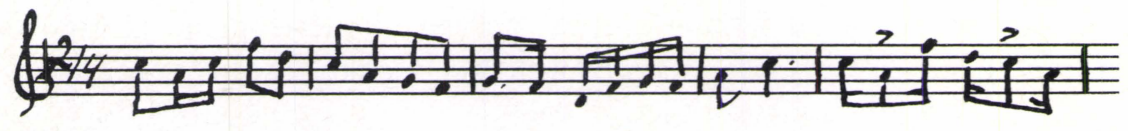

Och från omslagsbilden från en vanlig onestep under 10-talet "Mumlin' Mose" såg lyssnarna tydligt vilken hudfärg Moses hade: 


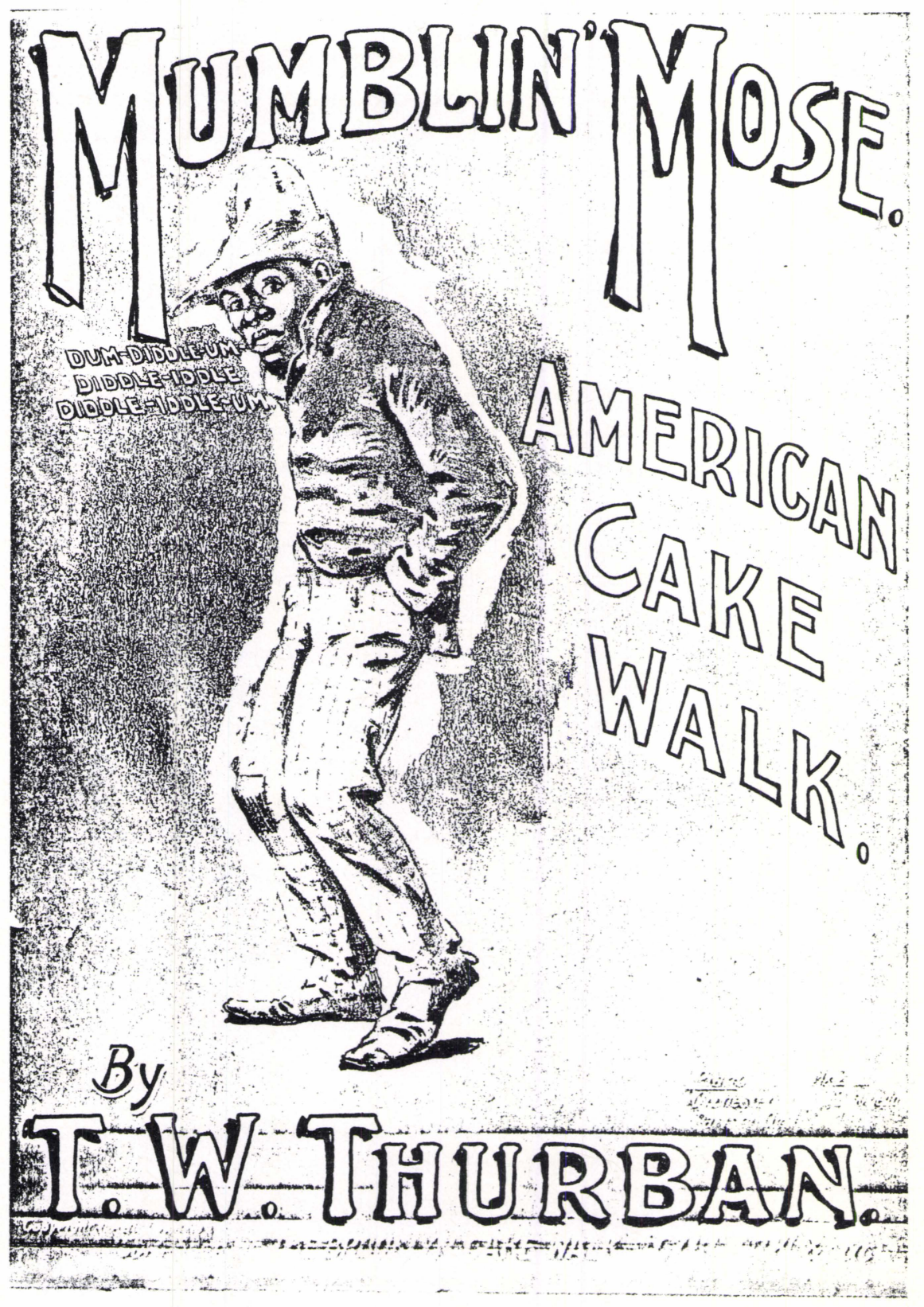


Andra stora onestep som på 10-talet gav likartade associationer var C Ekbergs "Kicki, Nigger-Ballad och onestep" och sångaren Jean Claessons succés "Zuzu - eller en kärleksballad från Zululand". Båda dessa sånger hade humoristiska och "exotiska" texter om kärlek.

Liknande musik kunde emellertid också ha omslagsbilder på indianska indianer (Kerry Mills "Red Wings", Neil Morets "Silver Wings", "Hiawatha" /den senare fick s s svensk text/ $\mathrm{m} \mathrm{fl}$ ). Ju längre fram i tiden vi kommer desto mer förbleknar dessa färgade omslagsbilder; på 1920-talet kan en onestep handla om i princip vad som helst.Beträffande synkoperna i de amerikanska onestepen är det odiskutabelt att dessa rytmiska strukturer innebar något nytt. Helt unika var dock inte dessa eftersom likartade rytmer då och då uppenbarar sig i underhållningsmusik och operettmelodier med ungerska-zigenska anspråk.

Det som talar emot att onestep uppfattades som en afro-amerikansk musik, var att skivorna med onestep etc aldrig spelades in av färgade musiker, att musikstilen sedan början av seklet sakta men säkert kommit in i Sverige - utan hjälp av färgade musiker, att den i klingande form i mycket liten grad alls avvek från övrig dansmusik och populär musik överhuvudtaget. De associationer man, tack vare omslagsbilder och text, fick till färgade människor, antingen dessa uttryckligen eller underförstått antogs befinna sig i USA eller Afrika, var av rolig eller exotisk art och innebar att ingen identifiering med den egna svenska personligheten kunde ske. Musikstilen förknippades inte med någon särskilt ungdomskultur, texterna uppfattades inte som något hot mot samhället utan det fel konservativa och kyrkliga kretsar såg med musiken låg i dess dansfunktion, dvs att pardans utan sträng socialkontroll var det samma som synd. Varken twostep eller onestep kan därför uppfattats som afro-amerikansk musik. Däremot har de troligen fört med sig associationer till USA, det stora amerikanska framtidslandet i väster dit så många svenskar hade utvandrat.

\section{Fransk schottish-foxtrot.}

När världskriget slutat importerar musikhandlarna fler och fler melodier som inte längre benämns onestep; det står foxtrot på noterna. Ernst Rolf, den i Sverige då mest betydande underhållningsartisten, lanserade exempelvis en mängd franska schlager av Christiné, Scotto, Castillon $\mathrm{m}$ fl. Rolf sjöng många av dessa på sin berömda kabart på restaurang Fenix Stockholm, liksom han sjöng in vissa på grammofon. Det intressanta är nu att flera av Christinés tidiga succéer kallades "schottish", bl a "Petite Tonkinoise", som han gjorde tillsammans med Scotto. Några år senare omnämns 
i Rolfs förlagskataloger $(1918,1920)$ melodier av snarlik karaktär för "foxtrot (onestep)". Men eftersom flera av dessa är komponerade i mitten av 10-talet, innan termen foxtrot hade slagit igenom i Frankrike, är det sannolikt förlaget (Rolfs) som skrivit dit dessa etiketter. Som tempobeteckning för dessa melodier står det nämligen oftast "moderato" eller "allegro moderato":

7. Petite Tonkinoise. Schottish. Scotto et Christiné.

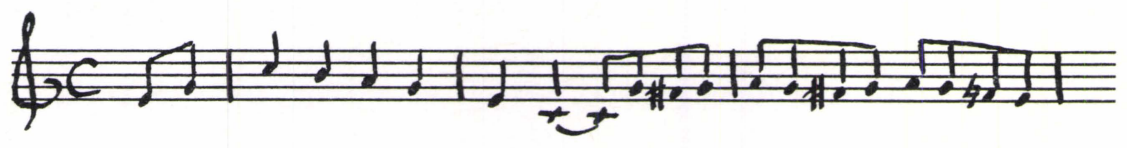

8. I en park så underbar. Foxtrot (onestep). Christiné.

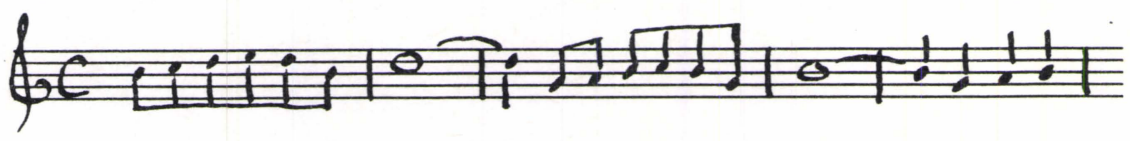

9. Nej-Nej-Nej (omnämns som "melodi" /min anm/) Christiné.

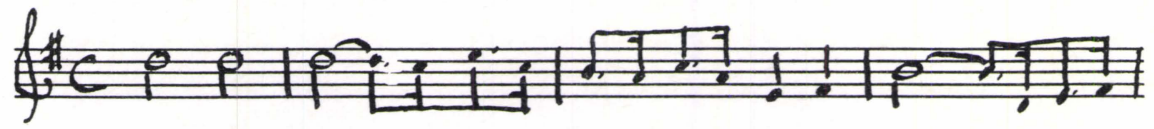

Början av några franska schottis-foxtrot

Som framgår av dessa melodier var likheten med (svensk) schottis mycket stor, och det är troligt, att en av förklaringarna till Rolfs stora framgångar med dessa franska "schottish-foxtrot-onestep" berodde på denna likhet. Han menade själv att han lanserade något nytt och fann att publiken som regel blev begeistrad (se i Svenska Dagbladet 14/10 1917, Aftonbladet samma datum, Ericsson 1968:101f, ).

En annan av Rolf framgångsmelodier under sent 10-tal var "I Honululu" (The Leightons, sv text S S Wilsson), som också är påfallande lik Christinés melodier. Den kallades förstås för foxtrot liksom de flesta engelska och amerikanska melodier i 4/4-takt då gjorde. Många av dessa foxtrot började allt fler människor förstå som amerikansk "jazz". 


\section{Vad jazz var.}

Att jazz var amerikansk dansmusik var säkerligen bekant för de flesta svenskar i början av 20-talet. Få tänkte på den som afro-amerikansk musikform. Reaktionerna på denna typ av dansmusik blev våldsamma. I tidskrifter och tidningar angreps den av musiker, kulturpersonligheter och "vanliga" människor (se Edström 1982, Kjellberg 1985). Orsakerna till detta var många: vissa kritiker sköt in sig på det allmänna oväsendet, frenesin och uppsluppenheten i den musik man via skivor eller på ryktesvägen fick höra (eftersom många av de tidigaste orkestrarna som kallades för jazzorkestar verkligen hade en stor arsenal av ljud- och rytminstrument fanns det särskilt $i$ början fog för epitetet "american noise"). Många var förbittrade och moraliskt indignerade på de olika pardansstilarna som följde med i kölvattnet (foxtrot, shimmy, senare charleston $\mathrm{m} \mathrm{fl}$ ), och inte minst att restaurangerna började arrangera "jazz-dans" och anställa "jazzorkestrar". Musiker var förargade för att de inte kunde spela den nya musikstilen; att utländska musiker (särskilt engelska) kom hit och fick jobben. Och för första gången observerade man nu att en viss ungdom tog till sig den nya musikstilen, jazzen som sin egen (det förargade också många). Men det var en begränsad ungdomsskara som hade ekonomiska och sociala möjligheter att möta denna nya musik. Som Karl-Gerhards berömda text "Jazzgossen" (till en dansk melodi) och andra vittnesbörd visar, var det huvudsakligen söner och döttrar bland storstädernas välbeställda borgarskap som detta intresse var möjligt att odla.

Generellt betydde foxtrot den nya lätta typ av dansmusik, som man jazzade $=$ dansade till på dansbanor och restauranter. Schlagerna var ofta stöpta i denna stil. Deras svenska innehåll, att de sjöngs på svenska av svenska sångare, huvudsakligen spelades av svenska musiker (en och annan kapellmästare hade förstås engelskt namn, och var kanske också engelsman), medförde därför att människorna under 20-talet sällan eller aldrig tänkte på foxtrot eller på jazz som färgad musik, eller som man då sade på "negermusik". Förutsättningarna för att detta överhuvudtaget skulle ske finns först från och med mitten av 20-talet, i och med att färgade orkestrar besöker Sverige, och senare då tonfilmen slår igenom på 30-talet, dvs då allt fler musiker får klart för sig vad det innebär att spela i s k "hot" stil, att färgade musiker som Louis Armstrong spelade på ett annorlunda sätt än vita musiker. Att jazz för de ledande vita och färgade musikerna $i$ USA inte var detsamma som amerikanska foxtrot-schlager (i s k Tin Pan Alley stil), var det mycket få svenskar som hade klart för sig under 20talet. Medvetandet om detta ökar långsamt först fr o $\mathrm{m}$ de första åren under 30-talet. 
Tvärtemot vad man kan tro, gick den övervägande majoriteten av kända foxtrot-schlager under 20 - och 30-talen inte i en utpräglad svängig stil med många synkoper, eller hade en avancerad "jazzig" harmonik. Oerhört få melodier hade melodiska drag som påminde om "blue notes", eller hade ö h t några "bluesiga" drag. Som jag visat i annat sammanhang, går många foxtrot som skrevs i USA och Europa i en internationellt gångbar "kompromisstil", eller liknar de mest marscher, har tyskt eller franskt påbrå (se Edström 1988). Bland tidens mest populära foxtrot finns faktiskt melodier som mer har att göra med schottis än något annat.

\section{Svenska bondfoxtrotar.}

När vi lämnade schottisen ur sikte i början av seklet försvann den in i det som brukar kallas gammaldans. Man fortsatte således att dansa schottis på logar och på utedansbanor lördag efter lördag, år efter år. Man dansade till tidigare kända melodier, till nykomponerade melodier, men det förekom säkert också att man prövade twostep- och onestepsteg till de gamla melodierna, liksom man kunde dansa schottis till Rolfs Christiné-melodier på 10- och 20-talet.

Under 1920-talet skrivs många framgångsrika schlager som "Te dans med Kalstatöserna" (Uppström) från 1920, "Bonnjazz eller Johan på Snippen" (G R Wahlberg) från 1922, "Den gula Paviljongen" (Redland) från 1923, "Trollebo-schottis" (Sundquist/1924/), "Han har blivit mycket bättre nu på gamla dar" (Rolf /1926/), "Jag är ute när gumman min är inne" (Sylvain /1926/), "Rialajazzen" (Lindberg /1928/) osv, som än kallas för foxtrot, än för schottis, ja, Sundquists melodi anges $\mathrm{t}$ o m som fox-schottis (Musikaliska Knutens förlag). Man kan faktiskt säga att vilken stil eller blandning som helst kan förekomma i melodiernas namn, som underrubriker eller som tempoanvisningar. Detta vittnar melodier som "Jazzflickans hambo", "Jungman Jansson polka - en folklig jazz", "Dragspelsjazz" av Larsson i Hult /!/ eller "tempo Bonna-jazz" om.

Mot denna bakgrund är det lätt att förstå musikern och skriftställaren G Rybrants litania år 1928:

Den svenska schlagerproduktionen har råkat in i en återvändsgränd. Det är samma återvändsgränd som den svenska filmen begav sig in i för några år sedan... Våra jazzfurnisörer förse oss nu med bondvalser, sjömansvalser, skepparvalser, bondjazzar (bara namnet är ju ett monstrum) med samma maniska envishet som våra filmfabrikörer på sin tid försåg oss med bondfilmer... Den svenska schlagern idag är en bondvals, en schottis eller en polka. Därmed har vi avlägsnat oss femtio år från det 
övriga Europa, för att inte tala om Amerika... Och vad har vi fått för foxtrotar $\mathrm{i}$ sommar? "Rialajazz" (en ny bondbit), "Inte gör det mej nå't" (typisk schottis)... Har man inte övergivit den väsnas-på-allesammans-på-en-gång-taktik som utmärkte de första åren i jazzens nordiska stenålder? Det kan vara på tiden att komponera i amerikansk stil också. Sångbara melodier, intressant rytmik, inte bara punkterade åttondelar, intressant harmonik, inte bara tonika och dominant (Våra Nöjen 1928:27).

Rybrants åsikter stöds indirekt av den stort upplagda undersökning om vad radiolyssnarna tycker om utbudet $\mathrm{i}$ den svenska radion i slutet av 20-talet. Man finner där att det människorna, särskilt på landsbyggden vill ha mer program med är "gammal dansmusik, samt folkvisor och allmogemusik" (Radiotjänst 1929:316).

Vi finner $\mathrm{m}$ a $\mathrm{o}$, att många av tidens mest populära, sjungna och spelade schlager under sin samtid uppfattades som svenska melodier. Och även om få av dessa benämndes för schottis, utan av musiker och publik kallades för foxtrot eller bonnjazz, så betydde detta inte att publiken betraktade dem som särskilt amerikanska eller naturligtvis för afroamerikansk musik (att den lilla gruppen unga svenska jazzintresserade dansmusikerna hade en annan syn på schottis är en annan sak som inte påverkar den allmänna bedömningen för 20-talet).

Även texternas innehåll för denna typ av foxtrot som jag benämnt bonnjazz eller svenska foxtrot avspeglar detta faktum (Edström 1988). Dessa melodier handlar ofta om fest, komik, svensk natur, men också om dåtida aktuella händelser och personer som intresserade den svenska allmännheten, och i synnerhet dem som gick på revyer och/eller köpte grammofonskivor och noter. Det säger sig självt att det inte fanns ett uns av generationsproblematik i dessa texter; bonnjazz var inte en ungdomsmusik på 20-eller 30-talen. Slutligen måste också konstateras att både schottis och bonnjazz är utpräglad tonal musik, och att de ur melodisk, rytmisk, harmonisk och formmässigsynpunkt helt ansluter sig till en allmänn europeisk tradition.

\section{Amerikansk ljudfilm svänger.}

När författaren Erik Asklund i romanens form låter några jazzintresserade stockholmsynglingar spela dansmusik ute på landet, märker de strax att det inte bara går att spela de senaste amerikanska melodierna. En av pojkarna, Bullas, spelade som tur var även dragspel:

Han klämde i med en hambo så att det började rycka i tårna på bonden... -De blir 
kultis varenda kväll, sade Tjabo. Han kunde inte med de gamla bitarna. Bondvalser, hambotakter passade inte en ekenskis som Tjabo. Men Bullas såg belåten ut. Han skulle vinna många pigors hjärtan med sitt stora, svajiga dragspel (1934:331).

Ändock är det dock den smak som romanens "Tjabo" står för, som under 30-talet kommer att vinna terräng, även då samhällets förändring betraktas från ett landsortsperspektiv. För det är uppenbart att det sker en amerikanisering av kulturen i Sverige under 30-talet. Redan tidigare var det naturligtvis påfallande att en mängd idéer, vanor och varor importerades från USA. I Rolfs vårturné 1927 hade exempelvis Herbert Landgren sjungit kupletten "Ryck upp dig, Europa!"( Lindberg, Stevens):

Den faran har dykt opp för oss $\mathrm{i}$ gamla världen, att under årens lopp vi gått mot smittohärden. Och utan tanke på att vi generas så har vi börjat att amerikaniseras...

Strax innan ljudfilmen gjorde sitt segertåg över Sverige kring år 1930 - och samtidigt gjorde nästan hälften av Sveriges yrkesverksamma musiker arbetslösa- gav skriftställaren Gunnar Tannefors uttryck för liknande farhågor, när han konstaterade att eftersom $70 \%$ av all film görs i USA, kommer ljudfilmen att innebära en enorm amerikanisering av vår kultur. Och han hade inga höga tankar om den amerikanska kulturen (Våra Nöjen 1928:28). I början av 30-talet konstateras det ofta att ljudfilmerna har blivit det främsta mediet när det gäller att lansera nya melodier. Antalet biografplatser bara i Stockholm var då över 30000. Samtidigt ökade fortfarande antalet radiolicensinnehavare. När de värsta depressionsåren var överståndna i mitten av 30-talet, kunde den amerikanska musik- och nöjesindustrin återuppta sin framgångsrika offensiv i Sverige. De flesta av tidens mest kända artister, sångare, orkesterledare var amerikaner, och som nämnts anlände nu också allt fler färgade amerikanska jazzmusiker/orkestrar till Sverige. Swingvågen svepte in, samtidigt som allt fler ungdomar, huvudsakligen från medel- och överklass, lyssnade på engelska utsändningar med modern dansmusik, köpte amerikanska skivor, startade lyssnarklubbar ("spisarklubbar"), bildade dansorkestrar, slukade reklambladet/tidningen Orkester Journalens tips och råd etc.

För första gången fanns det nu socio-ekonomiska och kulturella förutsättningar för en större ungdomsgrupp, inte minst inom arbetarklassen (som ju tidigt började arbeta och fick egna pengar), att omskärma sig med en delvis annan och mer "hot" dansmusik, swing eller den tidens jazz, än den de äldre generationerna lyssnande på och dansade till.

$\mathrm{Ju}$ längre mot 40-talet vi kommer desto mindre betydelsefulla blir de gamla bonnjazzlåtarna. Schottis blir definitivt en gammal dans. Man 
dansade därför till foxtrot i swingtempo eller som slow-fox, man dansade vals och tango, samt kanske någon enstaka gång en gammaldansmelodi. För dem som hade fötts i början av 20-talet när "jazzen" först nådde Sverige, var i många fall därför modern dansmusik, schlager och den nya swingmusiken deras egen musik. Särskilt i storstäderna markerade vissa ungdomar, s k swingpjattar, ytterligare sin egen identitet genom att klä sig i avvikande kläder (precis som de $\mathrm{s} \mathrm{k}$ jazzgossarna hade gjort på 20-talets början).

Den moderna dansmusiken, swingen laddades med värderingar som många i de äldre generationerna inte förstod. Inom konservativa och kyrkliga kretsar började man t o m anse att ungdomens vanor var alltför förvildade; kampen mot det $\mathrm{s}$ k dansbaneeländet upphöjdes under 1939 till officiell utredningsnivå $\mathrm{i}$ och med att regeringen tillsatte en ungdomsvårdskommitt (se Frykman 1985, Edström 1982:151).

Inom dessa kretsar hörde man således i musiken drag som man såg som hotande och fördömde därför vissa delar av musikstrukturerna och inte sällan samtidigt de artister som sjöng eller spelade musiken. Mycket bekant är STIM-chefen Westbergs bannbulla över den unga Alice Babs (Bruér/Westin 1973:57, Agrell 1984:34). Och strax efter kriget skrev gymnasieläraren Erik Walles en idag ökänd skrift om jazzen, där han bl a radade upp följande omdömen som idag framstår som helt absurda och oöverträffbara:

Den har skapats av negrer.

Den har skapats av berusade negrer.

Den har skapats av berusade negrer i bordellmiljö

(som citerat i Bruér/Westin 1974:13)

\section{Vad betydde "jazzens" musikaliska strukturer?}

Som jag velat visa, var den musikaliska skillnaden mellan den tidigare dansmusiken schottis, rheinländer etc och de under tiden 1900-1920 nya dansmusiktyperna twostep och onestep märkbar, men på intet sätt väsenskild. De nya dansmusikstilarna var samtidigt tidens mest populära sånger, eller schlager som de kom att kallas. De flesta människor tänkte mycket litet på denna musik som amerikansk och sällan eller aldrig på den som en afro-amerikansk musikform (här $=$ de färgades dans- och populärmusik $\mathrm{i}$ USA, eller som motståndarna till denna musik nog kallat den på 20-talet för, negermusik), utan snarare som den nya tidens, glada och trevliga svenska dans- och schlagermusik. 
Medan således schottis och andra gammeldanser lever vidare bland utedansbanornas och logarnas gerillaverksamhet, dyker en ny fiende, jazzen, upp på storstädernas dansarenor kring år 1920. I efterdyningarna av det första världskriget, med fler biografer, fler grammofoner, s s radio, i en jämn ström av nya amerikanska dansstilar, var det omöjligt att inte förstå, att jazz och foxtrot kom från Amerika (USA). Jazzkungen Paul Whiteman var ju amerikan. Och att den kanske i Sverige mest berömde jazzkapellmästaren, Jack Hylton var engelsman motsade inte denna iakttagelse, eftersom Whitemans musik var så lik Hyltons (eller tvärtom!). Men eftersom med tiden allt fler svenska musiker, med svenska namn spelade denna musik, då alla schlagerna hade svenska texter, som regel handlade om svenska företeelser, och framförallt då den stora majoriteten av dessa foxtrot hade en musikstruktur som var mest europeisk eller helt svensk (bonnfox), så betraktades dessa foxtrot framförda i sina svenska sammanhang sällan som amerikansk musik, och väl aldrig som afro-amerikansk.

Först fr o m mitten av 30-talet börjar insikten om det klingande amerikanska i swing-melodierna att långsamt breda ut sig, liksom, inom musikkretsar och bland jazzkännare, uppfattningen att de bästa jazzmusikerna var färgade. Dessa insikter når därefter sakta men säkert även den stora allmänheten. Men samtidigt s a $\mathrm{s}$ bromsas eller motarbetas denna medvetenhet av att de unga generationerna socialiseras in i samtidens musikkultur på ett naturligt sätt, dvs man växer upp i ett svensk sammanhang, där man lyssnar på svenska schlager, hör på svenska Sonora-inspelningar (svenskt skivbolag), läser om den svenska skolflickan Alice Babs, varför man så småningom lär sig att sjunga bl a "Swing it magistern, swing it, ja det är tidens melodi" (som musikforskarna Brolinsen \& Larsen /1983/ påpekar var filmen med samma namn /och melodi!/ en familjefilm och inte en ungdomsfilm), men också stora 40-talssuccéer och schottis som U-P Olrogs "Samling vid pumpen och Schottis på Valhall". Dessa melodier liksom skolsånger som "Jag vet en dejlig rosa" eller "Vi går över daggstänkta berg, fallera" fungerade därför alla som svenska sånger. Visserligen innehåller "Swing it, magistern" några engelska ord, men därifrån var det långt till att sjunga hela schlagertexter på engelska. Detta var sällsynt även under 40-talet. Framtill 40-talet var engelska överhuvudtaget ett litet språk i Sverige. Långt fler talade och förstod tyska.

Skillnaden i "svenskhet" mellan "Bonnjazz" år 1923 och "Swing it, magistern" år 1940, för två olika svenska trettonåringar vid resp tidpunkt är därför marginell. Förutsatt att de musikelement som kommer in i en musikkultur inte är alltför avvikande, och att inlåningstakten inte är för snabb, kommer den samtida populärmusiken, för majoriteten av människorna alltid att vara deras egen. Hur nationellt detta "egna" upplevs som 
varierar från kultur till kultur, från tid till tid.

Som jag ser det betyder detta sammantaget, att massmediautvecklingen på 30-talet, musikfilmer, swing, orkesterturner etc, liksom på 40-talet boogie woogie och de allmänna kulturella effekterna av det andra världskrigets utgång, visserligen medförde en amerikanisering av populärmusikkulturen, men att för folkflertalet, inkl de uppväxande generationerna, man i huvudsak upplevde denna musik som sin egen, dvs som svenska foxtrot, om än vissa ibland hade svängiga amerikanska drag. Men man upplevde inte sin dagliga musik som afro-amerikansk. För insatta musiker, liksom, i slutet av 40-talet för dixielandtokiga läroverksungdomar stod det däremot klart, att deras musiktyper inte enbart var amerikansk, men heller inte afro-amerikansk, utan kanske snarare, om termen tillåts, som "afmerikansk", ungefär som pianisten och textförfattaren Povel Ramel beskriver situationen i sin berömda svenska "Johanssons boogie woogie vals" från 1944:

Från Harlem i New York till Tranås i Småland är faktiskt en ganska lång väg, men likväl så kom häromdagen en platta från Staterna hem till herr Johanssons teg.

Den speltes på grammofon utav hans jazzbitne son som varit i Stockholm och fröjdat på Nalen och Sveasalen.

Och Johansson blev förtjust tog fram sin bälg helt burdust och slog sig neder vid grammofonen och sonen i salen.

Så ändra han låten på äktsvenskt manér och ganska snart tog den fart från kvarter till kvarter,

\section{Dikotomier.}

Den amerikanske musikforskaren Charles Hamm stöder indirekt det hittills förda resonemanget, då han skriver, att han upprepade gånger fört fram åsikten:

- that the influence of black music on American popular song has been exaggerated 
by certain writers, and that it was more a case of white musicians skimming off quite superficial elements of black musik to add a faintly exotic touch to their songs, which remained alien to blacks. Rock'n roll presents a far different picture (Hamm 1979:408).

Hamm och många med honom hävdar därför samtidigt att den ungdomliga popmusiken från och med 50-talets slut kom att låta allt mer afroamerikansk. Ett annat sätt att bearbeta denna iakttagelse på (och detta sker också efter rock'n rollens segertåg i västvärlden), blev för flera musikforskare och andra författare att ställa upp skillnader mellan afrikansk/afroamerikansk och europeisk/amerikansk musik som dikotomier. I Sverige blev en artikel (1972) av psykologen och jazzkännaren Bertil Sundin mycket uppmärksammad och diskuterad. Påverkad av bl a den amerikanska musikforskarens Charles Keils tankegångar (1966) skrev han bl a att den afro-amerikanska musiken härstammar från samhällets botten i USA, att den är en icke-noterad musikform och att den bekostar sig självt, dvs säljs via massmedia i vinstsyfte. Han skriver också att den nutida popmusiken låter allt mer afrikansk (1972:273).

Precis som Keil ställde även Sundin upp en tabell där den europeiska musikens ställdes i motsatsställning till den afro-amerikanska. Om därför schottis och bonnfox tas som exempel på dansmusik som varit bland den mest populära eller dominerande för folkflertalet i Sverige fram till 1940talet, blir det intressant att jämföra med Sundins ena avdelning:

spontanitet, improvisation

sensibilitet

motorisk reaktion

direkt emotionellt uttryck

omedelbar belöning

alstrad känsla genom musiken

Det hör visserligen till saken att varken Keil eller Sundin kan (?) eller vill diskutera sina indelningar med någon precishet, men som jag förstår begreppen, passar de väl in på våra musiktyper: Schottis/bonnjazz frammanar således, med Sundins termer, en motorisk reaktion, har ett direkt emotionellt uttryck, som omedelbart kommer fram (belönas), det alstras en känsla genom musiken, tack vare dess spontanitet osv.

Om vi däremot jämför dem med Sundins andra avdelning:

ordning, klar uppbyggnad effektivitet 
intellektuell reaktion

emotionell återhållsamhet

fördröjd belöning

inneboende mening i musiken

- så verkar denna mycket sämre passa in. Men nu kommer det paradoxala; med den första indelningen (spontanitet...), avser Sundin faktiskt "Afroamerikansk tradition", och med den andra (ordning,...), "Europeisk tradition"!! Den svenska (europeiska) schottisen och bonnjazzen är således afro-amerikansk musik...

Att dessa uppdelningar verkar så upp-och-ned-vända har förstås sina förklaringar; Keil utgår i sin jämförelse med afro-amerikansk musik från europeisk konstmusik. Sundin skriver "europeisk tradition", men menar troligen samma sak. Som tidigare sagts, finns det dock ingen principiell musikstrukturell skillnad mellan, låt oss säga stiliserad dansmusik som en Haydn-menuett och en schottis, dvs mellan europeisk konstmusik i den meningen, och folklig dansmusik som schottis.

På något sätt jämför författarna således meloner med lingon eller hjortron med squash, och det är därför inte konstigt att jämförelserna blir konstiga kompotter. Det hade varit bättre om de anlagt ett funktionsmässigt synsätt; vilken funktion, vad används musiken till i de olika kulturerna, "den afro-amerikanska" och "den europeiska" och att man därefter analyserat förhållandena mellan musikens verkningar/musikens struktur i resp kultur. Dessutom, menar jag, är det farligt att göra så enorma och svepande generaliseringar som man gjort. Att europeisk konstmusik skulle känntecknas av "intellektuell" reaktion" är sant bara för en mycket begränsad människoskara, och gäller möjligtvis först för den $\mathrm{s} \mathrm{k}$ absoluta musikens lyssnare under 1800-talet och framåt. För majoriteten av alla européer har lyssnandet till konstmusik långt oftare inneburit "ett direkt emotionellt uttryck, alstrad känsla genom musiken" osv.

Detta innebär dock inte, att jag förnekar, att de europeiska forskare, som utifrån sina referensramar (de flesta tycker /liksom jag/ mycket om jazz /Sundin/, blues /Keil/ etc) kommit fram till dessa dikotomier helt har fel utifrån sina uppfattningar. Visst kan jag som europé förstå vad de kommit fram till, men inte poängen. Men det är klart, att det ultimativa testet på detta först kunde göras om man kunde finna en kulturfri (oavhängig) mätmetod, vilket dock inte är möjligt... Vad jag undrar är således om vi verkligen vet, att för Ewe-folket i Ghana deras folkmusik inte har en "ordning, klar uppbyggnad" (utifrån deras egna värderingsnormer)?! Eller finns det ingen "emotionell återhållsamhet" för den färgade lantarbetaren i USA:s söder, i de många gånger mycket symboliska och underfundiga bluestex- 
terna ?!

Kanske hade deras jämförelse blivit bättre om den gjorts mellan europeisk folkmusik och afro-amerikansk musik (folkmusik)? Nej, troligen inte. För som J Kamin skriver i sin avhandling existerar liknande kontraster mellan "Euro-American och Afro-American folkmusic" (1975:22, /Han stöder sig bl a på en artikel av A Lomax i American Anthropologist, dec 1959/). Kamin hänvisar bl a till texternas olika roll och rytmikens olikhet.

Den europeiska (amerikanska) folkmusiktradition man här jämför med, är naturligtvis ingen konstmusik, men den är lika lite en dansmusik, eller underhållningsmusik av nyare snitt. Men det är (var) schottis, bonnfox liksom "vanlig" foxtrot. Som jag ser det, borde man därför jämfört dessa musiktyper med afro-amerikansk musik. Eftersom all denna musik har liknade egenskaper och funktioner, hade det emellertid inte varit lika enkelt eller ens möjligt för författarna att konstruera några pedagogiska dikotomier. Tvärtom är det ju en allmän uppfattning, att förutsättningen för att det överhuvudtaget finns en afro-amerikansk musik, beror på att europeisk och afrikansk musik har så stora likheter att en blandning har kunnat uppstå. Men denna blandning hade således inte kunnat uppstå om musiken i de skilda länderna, kulturerna inte hade haft liknande funktioner.

Att rock'n roll och senare pop och rock blev den nya ungdomsmusiken är dock ett känt faktum. Och att dessa musiktyper är afro-amerikanska, åtminstone att kallas de för detta är väl omvittnat (jfr Lilliestam 1984). Vad jag avslutningsvis skall uppehålla mig vid är därför, hur afro-amerikanska dessa musiktyper är. Men jag skall även fundera på varför det inte kunde gått lika bra med schottis?

\section{Svensk afro-amerikansk musik, har den funnits?}

Brolinson \& Larsen (1983) beskriver allmänt de socio-kulturella förutsättningarna för att rock'n roll kunde bli den svenska ungdomens musik i slutet av 50-talet. Man nämner den positiva inställningen till USA, begreppet tonåring och deras köpkraft, skinnknuttar, ungdomsfilm, ungdomsradio, EP-skivan, föräldrarnas nya fritidsintresse, TV osv. En annan viktig faktor som ofta förbigås, är den nya attityd till uppfostran, s $\mathrm{k}$ "fri uppfostran" som bredde ut sig efter kriget. Här var målet att andvika att skapa en människotyp som blint lydde auktoriteter.

Som bekant anammade tonåringarna begärligt den nya dans- och musikstilen. Jag skall dock inte så mycket diskutera detta faktum, som att fundera över hur "afro-amerikansk" denna musik uppfattades vara. Jag skall först låta Brolinson \& Larsen slå an tonen: 
Rockens tidiga utvecklingsfas i USA genomsyrades av en medvetenhet om dess rötter i en svart tradition och därav betingade värderingar hos den äldre vita medelklasspubliken. En motsvarande medvetenhet saknades uppenbarligen helt $i$ Sverige (1983:13, min betoning).

För tonåringarna (och jag var en av dem) var det således svårt att höra in några afro-amerikanska drag i Elvis Presleys eller Bill Haleys musik. De var lika vita som vi, och inte hade vi någon aning om hur de färgade sjöng blues, gospel eller hade lyssnat på elektrifierad rhythm \& blues. För tonåringarna var detta en uppnosig, dansvänlig och härlig amerikansk musik. Detta lärde vi oss snabbt genom att varje vecka sluka Bildjournalen och gå på rock'n roll -filmer. De som hade lyckan att gå på en rock'n roll -konsert upplevde en kollektiv begeistran för de nya idolerna som bara kunde skrikas och levas ut. De som bodde "på landet" kunde möjligtvis vara med om någon tävling mellan de lokala rock'n roll -stjärnorna, som på hemmagjord engelska gjorde sitt bästa för att imitera de amerikanska förebilderna. Att texterna sjöngs på engelska var närmast en självklarhet.

Som Jan Ling (1980) hävdat äger under detta decennium det rum en genomgripande förändring av musikkulturen. Han skriver bl a att "USA lyckades skapa en kulturell satellit av Sverige, bl a med bistånd av oskyldiga personer som Elvis Presley" (1980:132). Men som Ling också beskriver, sköljde i början av 50-talet en nostalgisk våg av sällan skådad storlek över Sverige. Den som fick känslorna hos de vuxna människorna att svalla var sångaren Gösta Snoddas Nordgren, som med sin succé "Flottarkärlek" anslog en hembygdsromantik som gått som en röd tråd genom svensk schlagerhistoria. För de uppväxande tonåringarna betydde dock Snoddas föga.

Det konstateras också att rock'n roll gick tillbaka i slutet av decenniet. De svenska rockkungarna detroniserades av en andra våg amerikanska vita sångare som Paul Anka, Ricky Nelson, Frankie Avalon m fl - alla stöpta i stilar som hade mycket litet att göra med upprorisk rock'n roll. Avalon, skriver Charles Hamm:

sings with the voice of a high school student - basically sweet, untrained, tentative, incapable of sustaining a musical line. Its appeal is in its simplicity, its innocense, perhaps its very mediocrity (1979:414).

Sakernas tillstånd för den afro-amerikanska musikens del var därför i början av 60-talet mycket dyster. Men jag tror ändå, att det som inträffat var viktigt inte minst ur musikstrukturell synpunkt. Ungdomen hade snabbt socialiserats in i musikstrukturer som var olika den tidigare dansmusikens/ 
schlagernas/populärmusikens. Man hade fått möta ett känslomässigt utspel (och inte minst ett rörelsemässigt), blues-baserade låtar med få och enkla harmonier och formelaktiga melodistrukturer, oskolade röster till ackompanjemang av elgitarrer etc. Alla drag som fanns i afro-amerikansk rhythm $\&$ blues, men som i Sverige i huvudsak uppfattades som amerikansk ungdomsmusik.

Eftersom denna musik nästan alltid dessutom sjöngs på engelska, fanns det små möjligheter att uppfatta något påtagligt svenskt i dess identitet. $\mathrm{Nu}$ bekymrade detta inte den svenska ungdomen; allt amerikansk var bra. Det säger därför sig självt, att schottis inte kunde bli den nya ungdomsmusiken på 50-talet. Schottis stod för det som var gammalt och förlegat: för svensk landsbygd, för tillbakagång, för morföräldrarnas generation osv.

När nästa stora lyft för ungdomsmusiken inträffade, kom musiken och livsstilen från England. Beatles, Dave Clark Five, Rolling Stones m fl grupper slog igenom med en ungdomsmusik som var en korsning mellan amerikansk rock'n roll, country \& western och i varierande utsträckning, drag från engelsk populärmusik. Så vitt jag kunnat finna, har emellertid ingen någonsin skrivit, eller sagt att Beatles musik var afro-amerikansk. Men Beatles liksom de flesta andra grupperna spelade, och då särskilt i början av deras karriärer, även låtar av färgade rhythm \& blues och rock'n rollmusiker, som Chuck Berry och Little Richard, dvs man hade tagit till sig och behärskade vissa afro-amerikanska stilmedel som bluesformler, riffteknik och och själva bluesformen. Den grupp som kanske mest axlade de stilideal som funnits i den upproriska rock'n rollen var Rolling Stones, som byggde upp sin image som en motsats till de snälla och trevliga pojkarna i Beatles. Men Rolling Stones uppfattades varken i Sverige eller USA som en afro-amerikansk grupp:

Rock was the music of white, urban, middle- and upper-class Americans... Black Americans and the rural whites who made up the traditional country-western audience were not turned on by the Beatles, or Bob Dylan, or the Beach Boys, or Jefferson Airplane, or the Rolling Stones, or the Who (Hamm 1979:458).

Som jag förstår det, kom det dock under några år in en musik i Sverige som hade vissa afro-amerikanska drag. Det var musik som vilade på afroamerikanska traditioner som gospel och blues med några stänk av tidig jazz. Under 60-talet lyssnade man även i Sverige mycket på artister med "soul" i sig som Ray Charles och Aretha Franklin. Därtill kom ett nytt "sound" , "the Motown sound":

The 1960s also saw the rise of the first urban, black, Northern popular song ... quite 
Men frågan är, i hur hög grad Diana Ross and the Supremes och andra Motown-grupper var s a s afro-amerikanska grupper. Här varierar som alltid svaret beroende på vem som svarar. För den svenska publiken var det obestridligt att det var färgade amerikanska sångare, som till form och innehåll inte var så särskilt annorlunda än traditionell schlager (Hamm 1979:462). Det som var nytt var därför mer röstklangen och själva sångsättet:

The singing style of Motown artists had a great deal to do with black gospel music. The vocal style was rich, full-voiced, highly melismatic and filled with melodic ornamentation. The rhythmic underpinning was also firmly and obviously rooted in rhythm-and-blues and gospel musik." (Hamm 1979:460).

De afro-amerikanska dragen i denna stil var därför urvattnade, men de fanns, och uppfattades i Sverige för den stora publiken säkerligen som det nya, som man lystrade till, även om man kanske inte uppfattade att dessa stilmedel var så afro-amerikanska; jag menar det var svårt att föreställa sig en fattig färgad jordbrukarhustru i södra Alabama när man såg Diana Ross (et al). Möjligen uppfattades denna musik som afmerikansk. Detta etikett kunde möjligtvis också sättas på den bluesbaserade musik som engelska grupper som John Mayall Bluesbreakers under en kort tid på 60-talet nådde Sverige med.

Den fortsatta utvecklingen inom ungdomsmusiken och populärmusiken överhuvudtaget har medfört att en mängd olika musikstilar har kommit och gått, utan att de afro-amerikanska elementen i musiken (här = bluesformer, bluesmelodik, riff, begränsad harmonik) stärkts. Grupperna inom den progressiva musikrörelsen kring 1970 och framåt spelade sällan eller aldrig afro-amerikansk musik, utan här fanns en allsköns blanding av $\mathrm{s} k$ "psykedelisk musik", rock'n roll, visor, folkmusik osv. För dem som inte delade alla de politiska värderingar som fanns inom den progressiva musikrörelsen, uppstod därför ibland besynnerliga krockar mellan den ibland klart amerikanska rock'n roll -musikens associationer och de antikapitalistiska-amerikanska texternas budskap. Som litteraturvetaren Olle Thörnvall påpekat fanns emellertid inom musikrörelsen också ett betydande inslag av folklighet och en musik för alla, och han citerar en text av $\mathrm{T}$ Wiehe som bl a framfördes av den kända gruppen Hoola Bandoola Band:

Så stränga din fela och fatta din lur.

Vi ska skapa en allas musikkultur 
för männskor och gudar och växter och djur. Här är vi.

Vi är samma sort som ni. (som cit i Thörnvall 1982:12).

Samtidigt minns vi alla hur den svenska gruppen ABBA utvecklades till en internationell supergrupp, dvs man sjöng nästan alltid sina sånger på engelska i en internationellt anpassad populärmusikstil.

Det fanns dock inom musikrörelsen ett betydande undantag, en grupp; Peps Persson och hans Blodsband, som på ett förunderligt, men övertygande sätt lyckades kombinera afro-amerikanska stildrag med svenska texter, $\mathrm{s}$ k skånsk blues. Den förste som brukar nämnas som den som sjöng rock på svenska är dock Pugh Rogefeldt (1969). Att språket är ett viktigt tecken på att musiken för ungdomen började upplevas som alltmer svensk är odiskutabelt. Banbrytare för denna "riktning" var dock Owe Thörnquist som redan i slutet av 50-talet hade stora succéer med sina svenska texter till rock'n roll -liknande melodier. Dessa låtar ,"Han hade låda på magen" (Varm korv boogie), Diverse Julboggie $\mathrm{m}$ fl minns jag väl hur jag och mina klasskamrater sjöng till mitt hemmagjorda boogie woogie -ackompanjemang. Men troligen tog de äldre generationerna inte hans rock'n roll -liknande melodier på allvar, utan hörde dem som pastischer (jfr Brolinson \& Larsen 1983:81f). Ett annat bevis p̊̊ att delar av rock n'rollens stilmedel snabbt försvenskades finner vi i de nyinspelningar av gamla svenska schlager och foxtrot som gjordes i början av 60-talet. Så spelade exempelvis den svenska popgruppen The Adventures in den kanske mest svenska av alla bonnjazz från 20-talet, Wahlbergs "Bonnjazz eller Johan på Snippen".

De enda betydande grupper som därför under 70-talet och framåt har bevarat vissa afro-amerikanska stilelement som bluesformer, riff och andra drag i sin musik är, som jag uppfattar det, s k hårdrockband. Men åter, fastän vissa av dessa afro-amerikanska musikelement finns där, uppfattas de inte som sådana av sin publik. Denna mot vuxenvärlden starkt avgränsade musik, speglar snarare liknande värderingar och känslor som Elvis tidiga rock'n roll, som Rolling Stones musik gjorde för sina generationer: dvs upprorisk, fräck, sexig, amerikansk, nutida, urban ungdomsmusik, som både används som kuliss och som identifikation. Hur amerikansk man uppfattar denna musik, varierar sannolikt mycket och beror på vilket band, vilket land som diskuteras. Få svenska ungdomar tänker väl på den svenska gruppen Europes musik som amerikansk; snarare som svensk eller europeisk(?). Samtidigt har gruppen, av allt att döma, stora framgångar i USA, men då sannolikt hos vita arbetar- och medelklassungdomar och inte 
hos färgade.

I en "objektiv" mening finns således vissa afro-amerikanska drag i rock'n roll på 50-talets slut, i vissa engelska gruppers musik på 60-talet, i "Motown"-soundet, i hårdrockmusik på 70-talet och framåt. Men i en subjektiv mening har de, menar jag, sällan eller aldrig uppfattats. Afroamerikanska stilelement i svensk populär- och ungdomsmusik har därför aldrig funnits i Sverige under 1900-talet, eller har möjligtvis uppfattats endast under en kortare period under 60-talet för att sedan åter försvinna ur människornas medvetande.

\section{När kommer schottisens renässans?}

Upprinnelsen till denna sista rubrik är egentligen två: dels råkade jag se ett program på svensk TV om en ny populär dans- och ungdomsmusik bland tjeckoslavisk-, polsk- och tyskamerikaner i dagens USA, dels fick jag höra en melodi "Persson ifrån stan" med Peps Blodsband från 1975 (sonet 2572). Därefter var jag inte lika säker på att svaret på frågan "när kommer schottisens renässans?" måste vara "aldrig". Om jag börjar med Peps, visar det sig, att det går alldeles utmärkt att använda en gammal svensk schottisliknande foxtrot som utgångspunkt för en reggae-liknande tolkning. Peps har melodin från sin far, men det är i allt väsentligt en version av en stor svensk filmschlager från 1931-32, "Köp Hjärtan" eller som den är mest känd som "En liten amulett" (Sylvain, S S Wilson). Ur musikalisk synpunkt finns det således inget hinder för att schottis skulle kunna "reggaefieras", rockas upp etc. Efter denna skiva gjorde dessutom Peps Person många liknande blandningslåtar. Kanske är således schottisens storhetstid så avlägsen, att en sådan blandningstyp idag skulle kunna uppkomma?! Men det behövs nog fler faktorer för att en inbrytning i den vanliga ungdomsmusiken skall kunna ske.

Viktigare för svensk schottis kan vara det som händer i dagens USA. En musikstil, som under 80-talet upplevt en renässans bland ovan nämnda befolkningsgrupper, är visserligen inte schottis, men den stilistiskt mycket närliggande polkan.

Polka, de gamla hemländernas dans- och underhållningsmusik har således nått en enorm popularitet, men inte bara bland de äldre generationerna, utan också bland de yngre som upptäckt, att det går lika bra att dansa till polka, lika bra att lyssna på polka, lika bra att sjunga nutida (engelska) texter till polka som det går till rock. Polkan är $\mathrm{m}$ a o lika mycket en ungdomsmusik inom dessa grupper som hårdrock är för svensk ungdom. 
Men det är klart, skall polkan/schottisen får en renässans i Sverige, fordras det att många ytterligare faktorer skall sammanfalla: polkan måste bli mycket mer populär i USA, den måste helst stå för en ny livsstil/klädstil, den måste lanseras i Europa och s s även i Sverige av kända artister osv. Och $D \AA$ kan det hända att någonting inträffar! Men det är uppenbart, att chanserna inte är så stora...

I dag lyssnar mindre grupper på särskilda radioprogram för blues och soul. $\AA$ andra sidan fortsätter man i några reservat, bland vänner av gammal dansmusik och på centerpartiets fester, att dansa den gamla hederliga schottisen och en och annan bonnjazz. Men den stora majoriteten av den svenska befolkningen lyssnar på svensk-amerikansk populärmusik, som ur strukturell synpunkt visserligen ibland kan beskrivas som afmerikansk, som som sällan eller aldrig uppfattas som sådan.

\section{Litteratur}

Asklund, E

1934 Fanfar för fem trumpeter. Stockholm.

Brolinson, P-E \& Larsen, $\mathrm{H}$

1983 Rockens introduktion i Sverige. Musikvetenskapliga institutionen Stockholms universitet. (Finns även något mer utarbetat skick med titeln: När rocken slog $i$ Sverige - Svensk rockhistoria 1955-1965. Falköping 1984).

Brur, J \& Westin, L

1974 Jazz. Musik, människor, miljöer. Stockholm.

Czerny, P \& Hofman, H P

1968 Der Schlager. Berlin.

Edström, K-O

1982 På Begäran - Svenska Musikerförbundet 1907-1982. Stockholm.

1988 Schlager $i$ Sverige 1910-40. Stockholm (under utgivning).

Ericson, U M

1968 Ernst Rolf. Stockholm.

Frykman, J

1985 "Vem bryr sig? - Generationsmotsättningar som moraliskt problem". I: Uppväxtvillkor $\mathrm{nr} 2$, s. 65-81, 1985.

Hamm, Ch

1979 Yesterdays - Popular Song in America. New York.

Helmer, A

1972 Svensk solosång 1850-1890. Uppsala. 
Kamin, J L

1975 Rhythm and blues in White America: Rock n'roll as acculturation and perceptual learning. Diss.

$\mathrm{Kiel}, \mathrm{Ch}$

1966 "Motion and feeling through music". I: Journal of aesthetics and art criticism, nr 2, s 337-349.

Kjellberg, E

1985 Svensk Jazzhistoria. Stockholm.

Lekstugan, Gamla svenska folkdansar. Utg. av Sällskapet Svenska Folkdansens Vänner. Stockholm 1903.

Lilliestam, L

1984 Om begreppet Afro-Amerikansk musik. Skrifter från Musikvetenskapliga institutionen, Göteborgs universitet.

Ling, $\mathrm{J}$

1979 "Folkmusik - en brygd". I: Fataburen, s. 9-34.

1980 "Populärmusiken under 1950-talet". I: Svensk Tidskrift för Musikforskning, s 113-132.

1980 "'Upp, bröder, kring bildningens fana' Om folkmusikens historia och ideologi". I: Folkmusikboken. Red. Ling, M Ramsten och G Ternhag. Stockholm.

Radiotjänst. En bok om programmet och lyssnarna. Stockholm. 1929

Rosenquist, $\mathrm{H}$

1948 "Från vals till jitterbug". I: Det glada Sverige III. Stockholm.

Sundin, B

1972 "Musikkulturer: trycket på ungdomen". I: Ord och Bild nr 5, s. 272-275.

Tegen, $\mathrm{M}$

1955 Musiklivet i Stockholm 1890-1910. Stockholm.

1986 Populär musik under 1800-talet. Stockholm.

Thörnvall, O

1981 Svensk rocklyrik. Litteratur och samhälle. Meddelande från Avdelningen för litteratursociologi vid Litteraturvetenskapliga institutionen i Uppsala. Årgång 18.

Våra Nöjen, 1928 (Tidskrift).

Öhrström, E

1987 Borgerliga kvinnors musicerande i 1800-talets Sverige. Göteborg. 


\section{Summary}

\section{How did schottis become bonnjazz?}

The collectors of folkmusic in the 19th century and onwards paid almost no attention to the polka or to its relative, the schottis. They were all interested in what they considered to be older or even archaic Swedish folk music. Nevertheless, these types of dance music very fast became very popular not only among the bourgeoise but also among the working class and the agricultural population. Around 1900 numerous schottis were composed, and were printed as sheet music, often with covers showing scenes and people in the swedish country-side (ex. 1-3).

This popular dance- and entertainment music survived as "gammal dansmusik" in the following decades even if the interest of the growing music industry turned to new innovations as twostep, onestep and in the beginning of the $20 \mathrm{~s}$, jazz i.e. foxtrot. The coming of twostep and onestep coincided with the birth of public dancing. From the covers one can sometimes find drawings of negroes in USA or Africa, corresponding to titles like "Nigger-ballad and onestep" and "Zuzu - or a love ballad from Zululand" (cp. cover of Mumblin' Mose). The form and style of twostep and onestep were similar to schottis and marches (ex. 4-6). The only structural novelty was syncopated rhythms, which could, however, also be heard in Hungarian-Gipsy influenced operettas. In spite of the somewhat exotic covers, the humorous lyric, the fact that this music was never played by coloured orchestras and that it was used as dance and entertainment music in Swedish contexts meant that it (twostep/onestep) was looked upon as a new and apt music suited for the mood of the period. The origin of twostep and onestep didn't make them American. No one, of course, thought about it as a form of Afro-American (or whatever similar term) music.

In the first decade of this century the foxtrot appeared. Many of the hits performed by the famous Swedish artist Ernst Rolf were of French origin. They all had a strong resemblance to schottis (ex. 7-9). Very soon a special Swedish foxtrot style, known at the time as "Bonnfox" (Farmers foxtrot), became a success. The songs were always sung in Swedish. The lyrics often dealt with "Swedish" subjects: Swedish nature and festivities or contemporary events in the Swedish society. As before people thought of these foxtrots in their Swedish contexts, although one knew that "the king of jazz" Paul Whiteman was a white American. But one very seldom thought of this type of dance music as Afro-American, possibly as American. But as a rule it was considered to be Swedish popular music, or with a German term as "schlagers". 
It was thus not until the 30 s that the impact of the talking picture, the swing fever and the general development of Swedish society created new conditions. Among young people there was now a growing awareness of the prominence of coloured jazz musicians. Louis Armstrong and many other black jazz musicians visited Stockholm. Many dance musicians knew how to play "hot" or to play "straight" etc.

Still those influences were to a great extent contradicted by the ways a child is socialized into culture. This means that the differences in "swedishness" between a schottis in 1900 for a one Swedish teenager, a "Bonnfox" in 1925 for a second teenager, or the hit "Swing it, magistern" in 1940 for a third teenager are marginal. On condition that the foreign musical element/s that are incorporated into a musical culture are not too different, and that the tempo of acculturation is not too fast, the contemporary popular music for the majority of the people in a given culture will always be considered as their own. How national one feels this music to be varies from time to time, from culture to culture.

When rock'n'roll flooded Sweden in the late 50s there was no awareness among the young of the origin and history of this music. Elvis Presley was as white as his imitators in Sweden. For the first time it was now compulsory to sing in English. As a rule, to Swedish teenagers at that time this music seemed like splendid and impertinent dance music. Musically speaking, this was the first time they listened to blues forms, melodies with few and simple chords, riffs, and small orchestras with electric guitars. All these traits were the backbone of the Afro-American rhythm \& blues tradition, but to Swedish young people they were understood as white American youth music. This wave very soon calmed down, however, and a new nonprotest form of youth music arrived from USA, featured by singers like Paul Anka.

At the end of the years of the $60 \mathrm{~s}$, after the years when English groups like the Beatles, who of course were never seen as an Afro-American group, one can see how more and more Swedish groups started to use texts in Swedish. This was especially the case among groups in the important alternative youth music movement in Sweden known as "Musikrörelsen", but it was not unusual to hear anti-American and anti-imperalistic texts sung to music that had strong American or even Afro-American connotations. In this decade, many old "schlagers" from the 20s and onwards were also recorded by different youth dance and music groups. A third "paradox" in those days was the development of the Swedish group ABBA into a supergroup, singing in English in an international pop-music style. The only groups that retained some Afro-American influences in their music were the hard rock bands. At present the Swedish band Europe is among 
the most succesful bands in this vein, but I believe most Swedish teenagers look upon their music as more Swedish/European (!) than American or Afro-American.

From an "objective" point of view certain musical elements from the Afro-American tradition can be said to exist in the rock'n roll of the $50 \mathrm{~s}$, in the music of some English groups in the $60 \mathrm{~s}$, to some extent in the "Motown"-sound and in hard rock band (heavy metal) in the 70s and 80s. But from a "subjective" point of view those styles have never been understood as Afro-American music by the Swedish youth. So in reality popular music in Sweden in this century has mostly been heard and looked upon as Swedish. From a structural point of view it has more and more been understood to have incorporated many elements from American popular music, but was very seldom considered to be Afro-American music, at the most "American-Swedish".

Seen in this light, an article by the Swedish psychologist and jazz writer B Sundin was reflected upon. According to Keil (1966), Sundin lists the most important musical elements in European and Afro-American music as dichotomies. He also believes the pop music in the 70 s to sound more and more African. If we take the schottis or the bonnjazz as points of departure, it seems logical to understand this music as "spontanous, to give motory reactions, to give a direct emotional expression" (Sundin) etc, in contrast to "order, effectivness, intellectual reaction" (Sundin) etc". For Sundin, this is not the case, since in his thinking, in his dichotomy, European music, and hence schottis etc, is characterized with the terms "order, effectiveness, intellectual reaction..." etc! To me those authors are comparing squash to cowberry, and not much will come out of this. It would have been far better to look at this problem from a functional point of view; which functions, what uses the music have in the different cultures - the "Afro-American" and the "European" - and then draw conclusions as to the relations between the musical structures in the cultures. Thus, if one had made comparisons between European and Afro-American forms of dance music as e.g. schottis and rhythm \& blues, it would have been much harder, if possible to construe any pedagogic dichotomies. 